\title{
Management Response to Online Customer Reviews in Distribution Channel: A Perspective of Manufacturers
}

\author{
Di Li \\ Wuhan University of Technology \\ McMaster University \\ lid69@mcmaster.ca
}

\author{
Ruhai Wu \\ McMaster University \\ wuruhai@mcmaster.ca
}

\author{
Hu Wang \\ Wuhan University of Technology \\ wanghu@whut.edu.cn
}

\begin{abstract}
In a distribution channel, where multiple manufacturers and retailers compete intensively, manufacturers' investment decisions on directly communicating with end consumers are strategic. In this study, we examined the interactive relationship between the manufacturers' management response strategies to online customer reviews and the channel structure formed in the online market. We collected data from Amazon.com, where the manufacturers, instead of the retailers, decide whether and how to respond to the customer reviews. The study illustrates the interaction of channel structure and manufacturers' management response strategies to the reviews. On the one hand, if a manufacturer invests in responding to customer reviews, more retailers are willing to carry its product. On the other hand, if more retailers sell a manufacturer's product, or if there are more intensive intra-competition in the retailer channels, the manufacturer is more likely to invest in management response.
\end{abstract}

\section{Introduction}

As marketing becomes more and more customeroriented, manufacturers' marketing strategy extends to direct communications with end consumers. For example, High Ridge Brands, one leading consumer packaged goods company, is communicating directly with millions of customers through email, social, mobile, earned and owned digital channels. This helps the company to build up a business valued at $\$ 415$ million in five years ${ }^{1}$. Directly communicating with end consumers helps manufacturers understand consumers' needs and preferences. Consequently, manufacturers can keep a high retention rate, acquire new customers and eventually increase profitability. Moreover, those manufacturers who maintain strong relationships with end customers appeal to retailers.

In a distribution channel, where intense competition exists among multiple manufacturers and retailers, manufacturers' investment decisions on direct communications with end consumers are complicated, as they interact with the channel structure of the distribution channel. On the one hand, the return of a manufacturer's investment on direct communicating with end consumers depends on the structure of the distribution channel. Intuitively, communicating with end consumers can increase the brand value of its products, consequently the sales from each retailer channel. The more retailer channels a manufacturer is using, the more benefit it can gain by the direct communication strategy. However, the competition among the retailers may weaken the total benefit to some extent. In addition, manufacturers' direct communication strategies may cause retailers' freeriding behaviors to reduce their marketing investments. As a consequence, the total sales of the distribution channel do not increase as expected and the manufacturer receives less benefit from its' direct communication strategy. On the other hand, the manufacturer's direct communication strategy affects the retailers' adoption decisions and consequently reshape the structure of the distribution channel. Directly communicating with consumers augments consumer satisfaction and brand recognition of the manufacturer's products and induces more retailers to deliver the products. Furthermore, the strategy represents a commitment by the manufacturer to reinforce the role of the retailer channels [32], which consolidates existing retailers' collaboration willingness. Nevertheless, increased brand equity may give

${ }^{1}$ https://www.forbes.com/sites/forbesinsights/2016/06/07/how-

leading-brands-are-winning-the-direct-to-customer-

conversation/\#48bc75a54fbd 
manufacturers more power than retailers [3,32], which distance the retailer from consumers [8]. It may hurt retailers' interests and impede the retailers' adoption decision. Besides, as directly communicating with end consumers requires substantial human and financial resources, manufacturers need to consider the cost as well when making their investment decisions. In summary, there is lack of theoretical understanding of how manufacturers optimize their direct communication strategy under different channel structures, and how their direct communication strategies restructure the distribution channel.

We use a unique context, Amazon.com, to explore the relationship between manufacturers' investment in communicating with end consumers and channel structure. In the online marketplace, retailers list products by different manufacturers in their channels and independently set retail prices. End consumers share their purchasing experiences through customer reviews, which are sorted according to the products but not to the retailers who sold the products. It's the manufacturers, instead of the retailers, to manage whether and how to respond to customer reviews. In this market, management response to customer reviews becomes a critical tactic of directly communicating with end consumers.

Our study aims to examine the interaction between the manufacturers' management response investment decision and the channel structure formed in the marketplace. Specifically, we consider two research questions: (1) How are manufacturers' management response strategies affected by the features of the channel structure? (2) How do manufacturers' management response strategies restructure the distribution channel? To address these questions, we build a theoretical model and empirically examine the relationship between channel structure and manufacturers' management response investment decision using a simultaneous equation model. The empirical results illustrate that the evolution of channel structure is altered by the customer reviews and manufacturers' responding strategies to the reviews. Specifically, positive customer reviews of a product allure retailers to sell the product. If the manufacturer invests in responding to customer reviews, more retailers are willing to carry its product. Our study also shows the impact of channel structure on the manufacturer's management response strategy. If more retailers sell a manufacturer's product, or if there are more intensive intra-competition in the retailer channels, the manufacturer is more likely to invest in responding to customer reviews.

This research fills a substantial gap in the literature on channel structure and manufacturer's marketing strategy of directly communicating with end consumers by examining the relationship between channel structure and manufacturers' management response to customer reviews. Moreover, it provides practical suggestions for manufacturers to invest in marketing communication strategy direct to end consumers under different channel structures.

\section{Literature review}

\subsection{The relationship between manufacturer' marketing strategies and channel relationship}

Some studies focus on manufacturers' brand related marketing strategies to end consumers in a distribution channel. Davis \& Mentzer (2008) suggested that retailers depend on manufacturers' brand equity to access to consumers [8]. Webster (2000) thought that manufacturers' brand is a key element in channel relationship as the brand can increase retailers' profit, gives the retailers credibility and protect retailers from competition from other resellers [32]. Zhang et al. (2017) showed that marketing strategies to improve consumers' brand loyalty are channel management strategies as with the increase of consumers' brand loyalty, retailers' dependence on suppliers increases [39]. In the industrial multi dyadic channel, Dahlquis \& Griffith (2014) found that industrial component suppliers (CS) will make marketing investment direct to indirect industrial buyers (IIB) to communicate its product-specific value to IIB and attract original equipment manufacturers (OEM) to use the CS's product [7].

A few studies have found that the effect of manufacturers' marketing strategies depends on the characteristics of the channel structure. Neslin et al. (1995) suggested that the benefit of manufacturers' advertising directly to end consumers depends on the reaction of both retailers and consumers [21]. Pauwels (2007) showed that the effectiveness of manufacturer promotions for consumer goods is affected by competitors' wholesale price reduction and retailers pass-through of promotion behaviour [23]. Zhang \& Xie (2012) discovered that when there are multiple symmetric retailers in the distribution channel, manufacturers' national advertising helps to generate sales of retailers that carry products of its brands, and as the retailer's number scales up, it contributes increasingly to add profits to both the manufacturer and the retailers in equilibrium [40]. Chutani \& Sethi (2018) have considered both national advertising effort and cooperation advertising effort decision of manufacturer and found that as the number of retailers in the distribution channel increase, local advertising effort by each retailer decreases and national advertising effort by each manufacturer increases [6]. 
Overall, the existing research has studied the relationship between manufacturers' marketing strategies and channel relationship. However, the research about the relationship between manufacturers' marketing strategies of directly communicating with end consumers and channel structure is limited. And the study about management response and its relationship with channel structure is rare. Next, we discuss some studies related to management response to online customer reviews.

\subsection{Management response to online customer reviews}

Many studies have examined the effect of online customer review (including rating and text) on product sales $[4,5,10,29,30,38,41]$ and consumer satisfaction [9,20]. Specifically, product and consumer characteristics are used as moderators in studying the effect of online review [2,11,13]. Moreover, some studies have examined the effect of online reviews on channel competition [15]. Existing studies have recognized the effect of online customer review, and the management response to online reviews have become an interest of academics. Most of the studies in this area focus on the impact of management response on firms' performance and consumers' satisfaction.

Some research focuses on studying the impact of management response on firms' performance, including firms' financial performance and firms' reputation. Ye et al. (2008) found that management response to online customer reviews is likely to influence consumers' perceived value of the brand and their purchase attention, and consequently increase product sales in the hotel industry [37]. Specifically, some important characteristics of management response, including the total number of management responses, the length and response time, have a positive relationship with hotel financial performance $[35,36]$. Besides, management responses can mitigate the effect of negative reviews on brand or firm evaluations [25,31] and improve firms' online reputation by increasing hotel ratings [24].

Some other studies focus on the effect of management response on consumers' satisfaction and attitude. Management response is part of firms' customer relationship management strategies, leading to more positive consumer attitudes towards the organization [16,28,33]. Responding to the online complaints has a positive effect on the company, including existing consumers' satisfaction and their continued loyalty to the company $[12,17]$. Specifically, Min et al. (2015) have found that management response includes empathy or paraphrasing statements for negative online reviews can even increase the satisfaction of potential customers [19].
In this paper, we focus on studying the relationship between management response strategy and channel structure by modelling the effect of the channel structure characteristics on management response decision and the effect of management response decision on retailers' adoption decision simultaneously. Studying this relationship will provide further insight into the effect of channel structure on manufacturers' direct marketing strategies to end consumers.

\section{Theoretical framework}

Given that we are modelling manufacturer's management response investment decision considering the structure of the distribution channel, we develop a theoretical framework to describe the relationship between manufacturers and their retailers in which manufacturers' management response decisions and the number of their retailers are determined endogenously. We consider a marketplace in which a few manufacturers sell their products through multiple independent retailers. The manufacturers, instead of the retailers, decide whether to respond to end consumers' product reviews to maximize their profits considering the characteristics of the channel structure. The retailers decide whether to adopt the manufacturers' products considering the former's management response strategies. The manufacturers' management response investment decisions interact with the number of their retailers dynamically and eventually reach an equilibrium state. The model is based on following general assumptions: (1) the manufacturers' marginal costs fixed; (2) all retailers pay the same wholesale price for a manufacturer's product.

We assume that there are $N$ retailers and $M$ manufacturers in the market. For the sake of simplicity, we assume each manufacturer sells one product in the market. Manufacturers make their management response decision depend on the channel structure. The wholesale price of manufacturer $j$ 's product is $W_{j}$, the marginal cost of manufacturer $j$ 's product is $C_{j}$.

Retailers decide whether to carry manufacturers' product. The decision function is as follows: if the retailer $i$ carries manufacturer $j$ 's product, $D_{i j}=1$; $D_{i j}=0$, otherwise.

Then the number of retailers who adopt manufacturer $j$ 's product is:

$$
n_{j}=\sum_{i=1}^{N} D_{i j}
$$

And the number of products that the retailer $i$ carries is: 


$$
m_{i}=\sum_{j=1}^{M} D_{i j}
$$

Retailer $i$ independently sets product $j$ 's retail price $P_{i j}$, and the sales of manufacturer $j$ 's product is $q_{i j}$. Retailer $i$ 's profit is as follows:

$$
\Pi_{i}^{r}=\sum_{j=1}^{M} D_{i j}\left(P_{i j}-W_{j}\right) q_{i j}
$$

Manufacturer $j$ 's management response strategy is $R_{j}$. we assume the cost of management response strategy is $\eta_{j} R_{j}$, the $\eta_{j}$ depends on the characteristics of a manufacturer. Then, manufacturer $j$ 's profit is as follows:

$$
\Pi_{j}^{m}=\sum_{i=1}^{N} D_{i j}\left(W_{j}-C_{j}\right) q_{i j}-\eta_{j} R_{j}
$$

We model the impact of channel structure on manufacturers' management response strategy as follows:

Manufacturer $j$ optimizes $R_{j}^{*}$ to maximize $\Pi_{j}^{m}$ Given the first order condition $\partial \Pi_{j}^{m} / \partial R_{j}=0$, we have

$$
n_{j} \frac{\partial q_{l j}}{\partial v_{j}} \frac{\partial v_{j}}{\partial R_{j}}=\frac{\eta_{j}}{W_{j}-C_{j}}
$$

where, $v_{j}$ is consumer perceived value of manufacturer $j$ 's product; $\frac{\partial q_{l j}}{\partial v_{j}}$ denotes how consumer perceived value averagely affects the sales in each retailer channel; and $\frac{\partial v_{j}}{\partial R_{j}}$ is the marginal impact of management response strategy on consumer perceived value. Equation (5) defines how the number of manufacturer $j$ 's retailers $\left(n_{j}\right)$ affects its management response strategy $\left(R_{j}^{*}\right)$.

We then model the impact of manufacturers' management response strategies on the number of retailers. Retailer $i$ decides to adopt the manufacturer $j$ 's product $\left(D_{i j}=1\right)$, if and only if its total profit when adopting the product is larger than that without adopting the product. When the retailer decides to sell the product by the manufacturer $j$, its profits from the other products decrease due to the substitute effect, $\Delta \Pi_{i j}{ }^{\prime}<$ 0 for $j \neq j^{\prime}$. Hence, the necessary and sufficient condition for the retailer $i$ to carry the manufacturer $j$ 's product is

$$
\left(P_{i j}-W_{j}\right) q_{i j}-\Delta \Pi_{i j^{\prime}} \sum_{j \neq j^{\prime}}^{M} D_{i j^{\prime}}>0
$$

We define the $\widetilde{\Delta \Pi_{l \jmath^{\prime}}}$ as the average of $\Delta \Pi_{i j^{\prime}}$, where $j \neq j^{\prime}$. Then, (6) can be approximated as

$$
\left(P_{i j}-W_{j}\right) q_{i j}>m_{i} \cdot \overline{\Delta \Pi_{\imath J^{\prime}}}
$$

\section{Hypothesis development}

Based on the above theoretical model, we develop nine hypotheses as shown in Figure 1. Due to the space limit, we briefly explain the reasoning for the first three hypotheses.

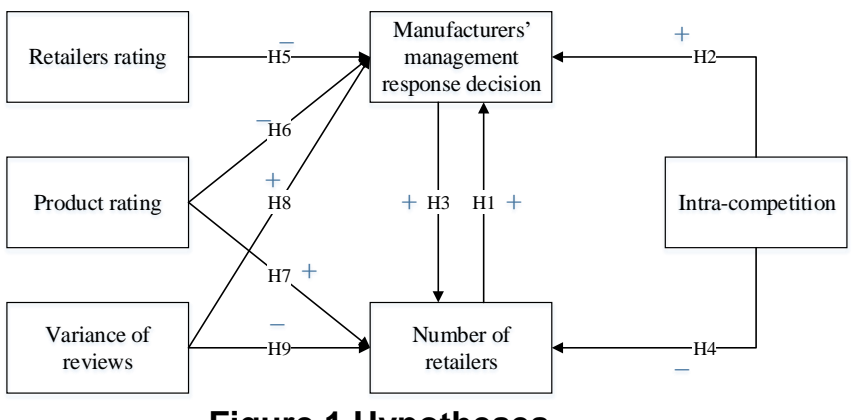

Figure 1 Hypotheses

Existing literature $[12,16,17,33]$ has shown that management response will increase consumer's perceived value, thus $\partial v_{j} / \partial R_{j}>0$. However, the marginal benefit on perceived value by the manufacturer's management response strategy is decreasing, $\partial^{2} v_{j} / \partial R_{j}^{2}<0$.

We now consider how the manufacturer $\mathrm{j}$ adjust its management response strategy $R_{j}^{*}$ according to the change of number of its retailers in short run operation. The right side of equation (5) is fixed in short run, as all the variables are determined by the manufacturer's characteristics. Thus, the left side of equation (5) should also keep constant, to achieve the optimal management response strategy. If more retailers join to sell the product, $n_{j}$ increases. Then the value of $\partial v_{j} / \partial R_{j}$ should decrease. Given $\partial^{2} v_{j} / \partial R_{j}^{2}<0, R_{j}^{*}$ increases. The background intuition is that when the increasing number of retailers $n_{j}$ adopt the product, per unit benefit from management response strategy increases, the manufacturer is more likely to invest in management response. Therefore, we generate the following hypothesis:

H1: As the number of retailers in the channel increases, the manufacturer's propensity to invest in management response.

As we know, the intra-competition exists as retailers' carry other competing products in the channel, and this intra-competition will affect the benefit of manufacturer's management response strategy. End consumers are more sensitive to product perceived value when the competition is more intensive in the retail channels. Thus, $\frac{\partial}{\text { intra_competition }_{j}}\left(\frac{\partial q_{i j}}{\partial v_{j}}\right)>0$.

Then with the intensification of intra-competition, the value of $\frac{\widetilde{q_{l j}}}{\partial v_{j}}$ will increase. Back to equation (5), to 
maximize the profit, the value of $\partial v_{j} / \partial R_{j}$ should decrease; therefore, $\mathrm{R}_{j}^{*}$ will increase. In other words, with the increasing intra-competition in the retailer channels, the manufacturer should invest in management response because management response can build brand differentiation and gain their competitive advantage among other manufacturers, consequently improve profit. Thus, we have the following hypothesis:

H2: The more intensive intra-competition in the retailer channels, the more likely for the manufacturer to invest in management response.

As we discussed above, management response can increase consumer's perceived value, and a higher perceived value can result in higher sales. Therefore, manufacturers' management response is supposed to increase retailers' sales. $\frac{\partial q_{i j}}{\partial R_{j}}=\frac{\partial q_{i j}}{\partial v_{j}} \cdot \frac{\partial v_{j}}{\partial R_{j}}>0$. If manufacturer $j$ invests in management response, the retailer $i$ 's sales $q_{i j}$ will increase, then the inequality (7) have a higher probability to hold. Therefore, retailer $i$ more likely to adopt manufacturer j's product, that is, $D_{i j}$ is more likely to be equal 1 . As $n_{j}=\sum_{i=1}^{N} D_{i j}$, the number of retailers in the channel will increase. We generate the following hypothesis:

H3: A manufacturer's management response strategy will induce more retailers to adopt the product.

\section{Empirical analysis}

\subsection{Data}

We use crawling techniques to track 1439 products with customer reviews from 441 brands daily in Wipe $\&$ Refill category on Amazon.com. We focus on studying the repeated-purchase products, such as household supplies, because management response is a common business practice in household supplies categories. The competition in the Wipe \& Refill category is intense. Manufacturers have a strong incentive to build a good relationship with both end consumers and retailers.

Our data period is from January 2018 to May 2018. We collect daily data on product characteristics (product rating, sales rank, etc.), channel structure (the number of retailers, the number of products a retailer carries, etc.), retailers' characteristics (retailer price, retailer rating, the total number of rating, etc.), online reviews, and manufacturer's management response. The online review data includes review posting data, helpfulness vote, review rating and review context. Management response data includes manufacturers' responding content, responding date and the corresponding review. Although there are more than 1400 products in the Wipe
\& Refill categories, only 430 products received new reviews during our data period. Totally, 5505 reviews and 713 management responses were posted during the period. As most products did not receive new reviews every day, we decide to use monthly data for the empirical study.

\subsection{Empirical model}

The theoretical model presented in the previous section suggests that the manufacturers' management response decision is a function of the channel structure, that is, the number of retailers in the channel, intracompetition. Meanwhile, the number of retailers in the channel is a function of manufacturers' responding decision. We are to examine the reciprocal relationship between manufacturers' management response decision and the number of retailers. We estimate a set of two simultaneous equations to describe how the equilibrium manufacturers' management response strategy and the number of retailers in the channel are determined. The first equation models manufacturers' strategic behaviours and explain the manufacturers' management response decision as an outcome of channel structure (including the number of retailers, intra-competition), retailers' credibility level, manufacturers type dummy, time dummies and product characteristics such as product rating and variance of the customer review ratings. The second equation describes the retailers' adoption behaviours and treats the number of retailers as an outcome of manufacturers' management response strategy, product rating, the variance of the customer review ratings, sales rank, the intra-competition and time dummies. Manufacturers' management response strategy reply it $_{\text {and }}$ the number of retailers retailernum $m_{i t}$ are the endogenous dependent variables in the simultaneous equation model, and other variables are exogenous variables.

The time dummies in both equations control the time effect on manufacturers' management decision and the number of retailers in the channel. The descriptive statistics of key variables in the model is in Table1. The empirical simultaneous equation model is as follows:

(1) reply it

$=\beta_{0}+\beta_{1}$ retailernum $_{i t}+\beta_{2}$ intra_competition $_{i t}$

$+\beta_{3}$ product_rating $_{i t}+\beta_{4}$ variance $_{i t}$

$+\beta_{5}$ retailer_rating $i t+\beta_{6}$ promanu $_{i}+\beta_{7}$ time $_{t}$

$+\beta_{8}$ time $_{t}+\beta_{9}$ time $_{t}+\varepsilon_{1 i t}$

(2) retailernum

$=\delta_{0}+\delta_{1}$ reply $_{i t}+\delta_{2} \log \left(\right.$ rank $\left._{i t}\right)$

$+\delta_{3}$ product_rating $_{i t}+\delta_{4}$ variance $_{i t}$

$+\delta_{5}$ intra_competition $_{i t}+\delta_{6}$ time $_{t}+\delta_{7}$ time $_{t}$

$+\delta_{8}$ time $_{t}+\varepsilon_{2 i t}$ 


\section{Estimation and result}

\subsection{Estimation}

The simultaneous equations model contains an endogenous dichotomous variable (management response decision) and an endogenous continuous variable (number of retailers in the channel). The two equations have exclusion restrictions for identification. The manufacturers' management response investment decision equation has two variables excluded in the channel structure equation - the average rating of retailers retailer_rating it $_{\text {_t }}$ and manufacturer type promanu $_{i}$. These two variables influence manufacturers' management response investment decision by affecting manufacturers' investment, but without any direct impact on the number of retailers in the channel. Similarly, the channel structure equation is identified by a variable excluded in the manufacturers' management response investment equation-the sales rank of the product $\log \left(\operatorname{rank}_{i t}\right)$. The benefit of the simultaneous method is that it captures causality between the two dependent variables. Because there are both dichotomous and continuous endogenous dependent variables in the model, traditional two-stage or threestage least squares estimation which is suitable for both continuous endogenous dependent variables equations will lead to biased estimates. Therefore, we use the twostage probit least squares estimation method [18], which correct the biased standard errors in the second stage of the estimation. The steps of the estimation approach are as following: (1) In step 1, the endogenous variables are fitted using all the exogenous variables. The dichotomous endogenous variable (management response decision) is estimated via Probit and the continuous endogenous variable (the number of retailers in the channel) is estimated via OLS. (2) In step 2, we regress management response decision and number of retailers on the include exogenous variables and predicted values of endogenous variables from step 1 . (3) In the final step, the outputted standard errors for each model in the second step are corrected using variance-covariance matrices.

Table 1 Descriptive Statistics of Key Model Variables

\begin{tabular}{|c|c|c|c|c|c|}
\hline & Explanation & M & SD & Min & Max \\
\hline retailernum $_{i t}$ & The average number retailers of the product $i$ at time $t$ & 6.75 & 6.05 & 1 & 28.7 \\
\hline $\operatorname{reply}_{i t}$ & $\begin{array}{l}\text { The possibility for manufacturer of the product } i \text { to respond } \\
\text { to customer reviews at time } t\end{array}$ & 0.11 & 0.32 & 1 & 0 \\
\hline intra_competition $_{i t}$ & $\begin{array}{l}\text { The average of the number of other products the product } i \\
\text { retailers carries (within the category) at time } t\end{array}$ & 37.12 & 41.54 & 0 & 193.7 \\
\hline product_rating $_{i t}$ & The average review rating of the product $i$ at time $t$ & 3.93 & 0.72 & 0 & 5 \\
\hline variance $_{i t}$ & The variance of the review rating of the product $i$ & 1.95 & 1.53 & 0 & 5 \\
\hline retailer_rating ${ }_{i t}$ & The weighted average of retailer rating of product $i$ at time $t$ & 4.87 & 0.18 & 4 & 5 \\
\hline $\log \left(\operatorname{rank}_{i t}\right)$ & $\begin{array}{l}\text { Log transformation of the average sales rank of the product } \\
i \text { at time } t\end{array}$ & 4.77 & 1.30 & 0 & 8.17 \\
\hline
\end{tabular}

\subsection{Result}

Table 2 presents the full estimates of the simultaneous equations model. We first look at the factors that determine manufacturers' management response investment decision. We find that the coefficient of the number of retailers (retailernum $_{i t}$ ) in the channel is significantly positive, supporting hypothesis $\mathrm{H} 1$. The result indicates that the number of retailers in the channel is positively related to the propensity of manufacturers to invest in management response. We find that the coefficient of intra_competition $_{\text {it }}$ in Equation 1 is positive and significant. This result support $\mathrm{H} 2$, that more intense the intra-competition in the retailer channels is, the more likely for the manufacturer to invest in responding customer reviews. These results provide an empirical evidence for our theoretical finding that a manufacturer's management response strategy depends on the structure of the distribution channel, including the number of retailers in the channel and intra-competition. Moreover, the coefficient of retailers' ratings ( retailer_rating $_{i t}$ ), is negative and significant, suggesting that when the average level of retailers' credibility is high, manufacturers are less likely to invest in management response.

Next, we analyze the factors affect the number of retailers in the channel. The coefficient of manufacturers' management response decision ( reply $_{i t}$ ) is positive and significant in Equation 2. This result is consistent with $\mathrm{H} 3$, which support our theoretical finding that manufacturers' management response strategies have a positive impact on retailers' decision to adopt the manufacturers' products. As the reply it $_{\text {is }}$ a dummy variable in Equation 2, the result indicates that if a manufacturer invests in responding customer 
reviews, more retailers are willing to carry its product, and else otherwise. The coefficient for the control variable, the sales rank of the product $\left(\log \left(\operatorname{rank}_{i t}\right)\right)$, which reflect the demand of the product and directly influence retailers' adoption decision, is negative and significant. This result indicates manufacturer's product with top rank attracts more retailers to adopt the product. Moreover, the effect of intra_competition it $_{\text {it }}$ on the number of retailers is negative and significant, suggesting that retailers are willing to carry product with less intensive competition.

In both equations, the time dummies are insignificant, suggesting that main effects not changed over time.

Table 2 estimation results

\begin{tabular}{|c|c|c|c|}
\hline \multirow[b]{2}{*}{ reply $y_{i t}$} & \multicolumn{3}{|c|}{ Model 1(Base Model) } \\
\hline & Coef. & $\begin{array}{l}\text { Std. } \\
\text { Err. }\end{array}$ & $P>t$ \\
\hline retailernum $_{i t}$ & $0.245^{* * *}$ & 0.044 & 0.000 \\
\hline retailer_rating ${ }_{i t}$ & $-1.363^{\star *}$ & 0.497 & 0.006 \\
\hline intra_competition $_{i t}$ & $0.009^{* *}$ & 0.003 & 0.004 \\
\hline promanu $_{i}$ & 0.468 & 0.308 & 0.128 \\
\hline product_rating $_{i t}$ & -0.115 & 0.175 & 0.511 \\
\hline variance $_{i t}$ & 0.167 & 0.104 & 0.108 \\
\hline time $2_{t}$ & 0.129 & 0.235 & 0.582 \\
\hline time $3_{t}$ & 0.234 & 0.238 & 0.325 \\
\hline time $4_{t}$ & -0.170 & 0.382 & 0.657 \\
\hline $\begin{array}{l}\text { intercept } \\
\text { retailernum } \\
\text { rt }\end{array}$ & 2.726 & 2.413 & 0.259 \\
\hline reply $_{i t}$ & $2.211^{* * *}$ & 0.396 & 0.000 \\
\hline product_rating $_{i t}$ & 0.438 & 0.437 & 0.316 \\
\hline variance $_{i t}$ & -0.397 & 0.286 & 0.165 \\
\hline $\log \left(\operatorname{rank}_{i t}\right)$ & $-0.944^{* *}$ & 0.279 & 0.001 \\
\hline intra_competition $_{i t}$ & $-0.047^{* \star *}$ & 0.007 & 0.000 \\
\hline time $2_{t}$ & -0.473 & 0.658 & 0.472 \\
\hline time $3_{t}$ & -0.904 & 0.658 & 0.170 \\
\hline time $4_{t}$ & -0.071 & 1.049 & 0.946 \\
\hline intercept & $16.323^{* * *}$ & 2.473 & 0.000 \\
\hline
\end{tabular}

\section{Robustness check}

\subsection{Using alternative estimation method}

In the main model, we use the two-stage probit least squares method [18] to estimate the simultaneous equations model. We now check the robustness of our findings using an alternative estimation method. We try to estimate the two equations in the simultaneous system separately. To estimate the Equation 1, we use the twostage estimator method described in Newey (1987), which is suitable for probit model with a continuous endogenous variable [22]. In Equation 1, the variable retailernum $_{i t}$ is a continuous endogenous variable, and reply $_{i t}$ is dummy dependent variable. The variable $\log \left(\operatorname{rank}_{i t}\right)$, which is in Equation 2 but not in Equation
1, is used as the instrument variable. To estimate Equation 2, we use the estimate method according to Wooldridge (2010) [34]. In the first step, we regress the endogenous variable on all the exogenous instruments via Probit, and then use the predicted value in first step as the IV in the 2SLS model. In Equation 2, the variable reply $_{i t}$ is dummy endogenous variable and retailernum $_{i t}$ is continuous dependent variable. Our analysis using such estimation methods yields similar results. However, because the simultaneous interaction between reply it $_{\text {and }}$ retailernum ${ }_{i t}$ is not considered in such methods, the coefficient of reply $y_{i t}$ which directly reflect the impact on retailernum ${ }_{i t}$, is greater than the coefficient in base model. The results present in Table3.

Table 3 Robustness checks

\begin{tabular}{|c|c|c|c|c|}
\hline \multirow[b]{2}{*}{ reply $y_{i t}$} & \multicolumn{2}{|c|}{$\begin{array}{c}\text { Model } 2 \\
\text { (Alternative } \\
\text { estimation } \\
\text { method) }\end{array}$} & \multicolumn{2}{|c|}{$\begin{array}{c}\text { Model } 3 \\
\text { (product features } \\
\text { as control } \\
\text { variables) } \\
\end{array}$} \\
\hline & Coef. & $\begin{array}{l}\text { Std. } \\
\text { Err. }\end{array}$ & Coef. & $\begin{array}{l}\text { Std. } \\
\text { Err. }\end{array}$ \\
\hline retailernum $_{i t}$ & $0.244^{* * *}$ & 0.045 & $0.270^{* * *}$ & 0.047 \\
\hline retailer_rating ${ }_{i t}$ & $-1.390^{* *}$ & 0.513 & $-1.368^{* *}$ & 0.533 \\
\hline intra_competition $_{i t}$ & $0.010^{\star *}$ & 0.003 & $0.010^{* *}$ & 0.003 \\
\hline promanu $_{i}$ & 0.467 & 0.315 & 0.412 & 0.312 \\
\hline product_rating $_{i t}$ & -0.119 & 0.178 & -0.111 & 0.185 \\
\hline variance $_{i t}$ & 0.166 & 0.106 & 0.191 & 0.109 \\
\hline time $2_{t}$ & 0.122 & 0.241 & 0.158 & 0.245 \\
\hline time $3_{t}$ & 0.237 & 0.243 & 0.282 & 0.248 \\
\hline time $4_{t}$ & -0.162 & 0.390 & -0.245 & 0.398 \\
\hline Unscented $_{i}$ & & & 0.387 & 0.258 \\
\hline Natural $_{i}$ & & & -0.433 & 0.236 \\
\hline AlcoholFree $_{i}$ & & & 0.422 & 0.318 \\
\hline HypoAllergenic $_{i}$ & & & -0.391 & 0.324 \\
\hline Sensitive $_{i}$ & & & -0.214 & 0.285 \\
\hline intercept & 2.874 & 2.492 & 2.549 & 2.569 \\
\hline $\begin{array}{l}\text { retailernum }_{i t} \\
\text { reply }_{i t}\end{array}$ & $12.911^{* * *}$ & 1.709 & $2.341^{* * *}$ & 0.373 \\
\hline product_rating $_{i t}$ & $0.668^{*}$ & 0.336 & 0.467 & 0.465 \\
\hline variance $_{i t}$ & -0.168 & 0.234 & -0.474 & 0.296 \\
\hline $\log \left(\operatorname{rank}_{i t}\right)$ & $-0.100^{* * *}$ & 0.253 & $-0.797^{\star \star}$ & 0.274 \\
\hline intra_competition $_{i t}$ & $-0.045^{\star * *}$ & 0.006 & $-0.046^{\star * *}$ & 0.007 \\
\hline time $2_{t}$ & -0.210 & 0.615 & -0.474 & 0.677 \\
\hline time $3_{t}$ & -0.777 & 0.616 & -0.939 & 0.676 \\
\hline time $4_{t}$ & -0.573 & 0.923 & 0.183 & 1.086 \\
\hline intercept & $9.810^{* * *}$ & 2.349 & $15.969^{* * *}$ & 2.610 \\
\hline
\end{tabular}

$* \mathrm{p}<.05, * * \mathrm{p}<.01, * * * \mathrm{p}<.001$

\subsection{Using product features as control variables}

We report results with the controls for the product features in Table3. Some specific features of the product may influence manufacturers' management response investment decision. Therefore, we try to use some product features as control variables to check whether manufacturers are more likely to respond to products with some specific features. The robustness check relies on the primary product features classified by 
Amazon.com, including Unscented, Natural, AlcoholFree, Hypo-Allergenic, Sensitive. We take these five features as dummy control variables to repeat our estimation. The results show that coefficients of these five dummies are insignificant, which indicates manufacturers will not tend to make a management response investment decision on a product with specific features.

\section{Discussion and conclusion}

In this paper, we present a theoretical model to analyze how are manufacturers' management response strategies affected by the features of the channel structure and how do manufacturers' management response strategies restructure the distribution channel? And we empirically test the hypotheses developed based on the theoretical model.

Our results show that channel structure affects manufacturers' management response investment decision. Firstly, As the marginal cost of management response is constant, the more retailer channels a manufacturer is using, the more benefit the manufacturer's management response strategy will generate. Therefore, the manufacturer is more likely to invest in responding to customer reviews. Secondly, the direct impact of intra-competition on manufacturers' management response decisions is significantly positive, showing that the marginal benefit of a manufacturer's management response strategy is high when its products competes intensively with competitors in the retailer channels. Besides, the average retailers' rating has significantly negative impact on manufacturers' management response investment decision. The high rating of retailers is a guarantee of the quality of goods and services, and the marginal benefit of manufacturers' management response strategies is low when the rating of retailers is high. Therefore, manufacturers have lower propensity to respond to the product. Finally, our results also show that manufacturers' management response strategies can attract more retailers to carry the product and alter the channel structure, as the manufacturer's management response strategy can promote the sale of retailers who carry its product.

Our empirical study also shows some other findings regarding the control variables. The sales rank of the product has a significantly negative influence on the number of retailers. The top sales rank stands for the high quality of product to some extent and is a guarantee for the high consumer demand, thus retailers are likely to adopt the product. Moreover, the intra-competition in the channel has a negative and significant impact on retailers' adoption decision as well. When the intracompetition is more intensive, the profit for retailers who adopts the manufacturer's product will decrease, thus less retailers will adopt the product.

This research contributes to the literature in several ways. First, we examine the effect of channel structure on manufacturers' marketing strategies of directly communicating with end consumers. Prior research focuses on the effect of manufacturers' marketing strategies direct to consumers on manufacturer themselves and retailers in the channel $[8,26]$. Although a few researchers have examined the effect of channel structure characteristics on manufacturers' marketing strategy $[6,23,40]$, these researchers ignored its reciprocal relationship with channel structure. Our results demonstrate that manufacturers' marketing strategy of management response interacts with channel structure. Second, we extend existing research on the importance of directly communicating with end consumers on firms' performance. Prior research has examined the importance of management response on product sales [37] and consumer satisfaction [12,17,19]. We extend this research by illustrating the importance of management response strategy on channel relationship management.

Our study provides managerial implications. The empirical findings suggest that when there are many retailers in a distribution channel, and there is intense competition among the products carried by the retailers, the manufacturer should invest in marketing strategies direct to end consumers. Moreover, retailers can take advantage of the manufacturers' strategies direct to end consumers when they make their product adoption decision because products which manufacturers invest in marketing strategies are supposed to have higher perceived quality.

This study has limitations that further research could address. First, we examined the manufacturers' management response decision on repeated-purchased products on Amazon.com. The manufacturers' management response behaviour of other types of product is rare on Amazon.com. If the data are available, we can compare manufacturers investment decision on management response in different product types. Secondly, we focus on manufacturers' management response decision. We do not analyze the characteristics of management response, such as the length of the management response content, and the corresponding reviews valence. Such analysis would offer a deeper understanding of manufacturers' responding strategies. Finally, we assume that the marginal costs for manufacturers are fixed. However, this could affect manufactures' strategy to respond to customer reviews. We will relax the assumption in the future study.

In conclusion, our study validates the interactive impacts between firms' direct communication strategies and channel structure. Specifically, it explores the 
complex impacts of the channel structure on manufacturers' management response to online reviews in a multi-channel distribution system. It offers manufactures guidelines for investment in marketing strategies direct to end consumers under different channel structure. It also gives insight into the further research about direct marketing strategies and channel relationship management.

\section{References}

[1] Ailawadi, K. L., Beauchamp, J. P., Donthu, N., Gauri, D. K., \& Shankar, V. (2009). Communication and promotion decisions in retailing: a review and directions for future research. Journal of Retailing, 85(1), 42-55.

[2] Baker, A. M., Donthu, N., \& Kumar, V. (2016). Investigating how word-of-mouth conversations about brands influence purchase and retransmission intentions. Journal of Marketing Research, 53(2), 225-239.

[3] Butaney, G., \& Wortzel, L. H. (1988). Distributor power versus manufacturer power: the customer role. The Journal of Marketing, 52-63.

[4] Chevalier, J. A., \& Mayzlin, D. (2006). The effect of word of mouth on sales: Online book reviews. Journal of marketing research, 43(3), 345-354.

[5] Chintagunta, P. K., Gopinath, S., \& Venkataraman, S. (2010). The effects of online user reviews on movie box office performance: Accounting for sequential rollout and aggregation across local markets. Marketing Science, 29(5), 944-957.

[6] Chutani, A., \& Sethi, S. P. (2018). Dynamic cooperative advertising under manufacturer and retailer level competition. European Journal of Operational Research, 268(2), 635-652.

[7] Dahlquist, S. H., \& Griffith, D. A. (2014). Multidyadic industrial channels: Understanding component supplier profits and original equipment manufacturer behavior. Journal of Marketing, 78(4), 59-79.

[8] Davis, D. F., \& Mentzer, J. T. (2008). Relational resources in interorganizational exchange: the effects of trade equity and brand equity. Journal of Retailing, 84(4), 435-448.

[9] Forman, C., Ghose, A., \& Wiesenfeld, B. (2008). Examining the relationship between reviews and sales: The role of reviewer identity disclosure in electronic markets. Information Systems Research, 19(3), 291-313.

[10] Godes, D., \& Mayzlin, D. (2004). Using online conversations to study word-of-mouth communication. Marketing Science, 23(4), 545-560.

[11] Gopinath, S., Thomas, J. S., \& Krishnamurthi, L. (2014). Investigating the relationship between the content of online word of mouth, advertising, and brand performance. Marketing Science, 33(2), 241-258.

[12] Gu, B., \& Ye, Q. (2014). First step in social media: Measuring the influence of online management responses on customer satisfaction. Production and Operations Management, 23(4), 570-582.

[13] Ho-Dac, N. N., Carson, S. J., \& Moore, W. L. (2013). The effects of positive and negative online customer reviews: do brand strength and category maturity matter? Journal of Marketing, 77(6), 37-53.
[14] Jørgensen, S., \& Zaccour, G. (1999). Equilibrium pricing and advertising strategies in a marketing channel. Journal of optimization theory and applications, 102(1), 111-125.

[15] Kwark, Y., Chen, J., \& Raghunathan, S. (2014). Online product reviews: Implications for retailers and competing manufacturers. Information systems research, 25(1), 93-110.

[16] Lee, C. H., \& Cranage, D. A. (2014). Toward understanding consumer processing of negative online wordof-mouth communication: the roles of opinion consensus and organizational response strategies. Journal of Hospitality \& Tourism Research, 38(3), 330-360.

[17] Lee, Y. L., \& Song, S. (2010). An empirical investigation of electronic word-of-mouth: Informational motive and corporate response strategy. Computers in Human Behavior, 26(5), 1073-1080.

[18] Maddala, G. S. (1983). Limited-dependent and qualitative variables in econometrics (No. 3). Cambridge university press. [19] Min, H., Lim, Y., \& Magnini, V. P. (2015). Factors affecting customer satisfaction in responses to negative online hotel reviews: The impact of empathy, paraphrasing, and speed. Cornell Hospitality Quarterly, 56(2), 223-231.

[20] Moon, S., Bergey, P. K., \& Iacobucci, D. (2010). Dynamic effects among movie ratings, movie revenues, and viewer satisfaction. Journal of Marketing, 74(1), 108-121. [21] Neslin, S. A., Powell, S. G., \& Schneider Stone, L. (1995). The effects of retailer and consumer response on optimal manufacturer advertising and trade promotion strategies. Management Science, 41(5), 749-766.

[22] Newey, W. K. (1987). Efficient estimation of limited dependent variable models with endogenous explanatory variables. Journal of Econometrics, 36(3), 231-250.

[23] Pauwels, K. (2007). How retailer and competitor decisions drive the long-term effectiveness of manufacturer promotions for fast moving consumer goods. Journal of Retailing, 83(3), 297-308.

[24] Proserpio, D., \& Zervas, G. (2017). Online reputation management: Estimating the impact of management responses on consumer reviews. Marketing Science, 36(5), 645-665.

[25] Rose, M., \& Blodgett, J. G. (2016). Should hotels respond to negative online reviews?. Cornell Hospitality Quarterly, 57(4), 396-410.

[26] Sigué, S. P. (2008). Consumer and retailer promotions: who is better off?. Journal of Retailing, 84(4), 449-460.

[27] Simpson, P. M., Siguaw, J. A., \& Baker, T. L. (2001). A model of value creation: Supplier behaviors and their impact on reseller-perceived value. Industrial Marketing Management, 30(2), 119-134.

[28] Sparks, B. A., So, K. K. F., \& Bradley, G. L. (2016). Responding to negative online reviews: The effects of hotel responses on customer inferences of trust and concern. Tourism Management, 53, 74-85.

[29] Sun, M. (2012). How does the variance of product ratings matter?. Management Science, 58(4), 696-707.

[30] Tang, T., Fang, E., \& Wang, F. (2014). Is neutral really neutral? The effects of neutral user-generated content on product sales. Journal of Marketing, 78(4), 41-58.

[31] Van Noort, G., \& Willemsen, L. M. (2012). Online damage control: The effects of proactive versus reactive webcare interventions in consumer-generated and brandgenerated platforms. Journal of Interactive Marketing, 26(3), 131-140. 
[32] Webster Jr, F. E. (2000). Understanding the relationships among brands, consumers, and resellers. Journal of the academy of marketing science, 28(1), 17-23.

[33] Wei, W., Miao, L., \& Huang, Z. J. (2013). Customer engagement behaviors and hotel responses. International Journal of Hospitality Management, 33, 316-330.

[34] Wooldridge, J. M. (2010). Econometric analysis of cross section and panel data. MIT press.

[35] Xie, K. L., So, K. K. F., \& Wang, W. (2017). Joint effects of management responses and online reviews on hotel financial performance: A data-analytics approach. International Journal of Hospitality Management, 62, 101-110. [36] Xie, K. L., Zhang, Z., \& Zhang, Z. (2014). The business value of online consumer reviews and management response to hotel performance. International Journal of Hospitality Management, 43, 1-12.

[37] Ye, Q., Gu, B., Chen, W., \& Law, R. (2008). Measuring the value of managerial responses to online reviews-A natural experiment of two online travel agencies. ICIS 2008 Proceedings, 115.

[38] Ye, Q., Law, R., \& Gu, B. (2009). The impact of online user reviews on hotel room sales. International Journal of Hospitality Management, 28(1), 180-182.

[39] Zhang, C., Zhuang, G., Yang, Z., \& Zhang, Y. (2017). Brand Loyalty Versus Store Loyalty: Consumers' Role in Determining Dependence Structure of Supplier-Retailer Dyads. Journal of Business-to-Business Marketing, 24(2), 139-160.

[40] Zhang, J., \& Xie, J. (2012). A game theoretical study of cooperative advertising with multiple retailers in a distribution channel. Journal of Systems Science and Systems Engineering, 21(1), 37-55.

[41] Zhu, F., \& Zhang, X. (2010). Impact of online consumer reviews on sales: The moderating role of product and consumer characteristics. Journal of marketing, 74(2), 133148. 